\title{
enquanto estratégia de fortalecimento do pensamento crítico/reflexivo na sala de aula e nos espaços comunitários de Macapá
}

O TEATRO DIALÉTICO enquanto estratégia de fortalecimento do pensamento crítico/reflexivo na sala de aula e nos espaços comunitários de Macapá

THE DIALECTIC THEATER a strategy of strengthening critical / reflexive thinking in the classroom and in communal spaces in Macapá

Luciane Souza Pereira lulytoler@hotmail.com Acadêmica de Licenciatura em Teatro pela Universidade Federal do Amapá-UNIFAP. Pós graduada em Docência do Ensino Superior, pelo Instituto de Ensino Superior do Amapá- IESAP

\section{José Flávio Gonçalves da Fonseca} flavio.g.f@gmail.com Professor Assistente do Curso de Licenciatura em Teatro da Universidade Federal do Amapá- UNIFAP; Área: Prática Pedagógica em Teatro. Mestre em Artes pela UFC (PPGARTES). Graduado em Teatro - Licenciatura pela Universidade Federal do Ceará - UFC. ArteEducador e Ator-pesquisador do Núcleo de Pesquisa, Estudo e Experimentação Cênica (NUPEC) da OFICARTE Teatro e Cia.

\section{Resumo:}

O principal objetivo desta pesquisa é trabalhar a dialética na sala de aula e espaços comunitários da cidade de Macapá-Ap, a partir de modelos de ação de Brecht e outros textos didáticos, também na perspectiva brechtiana. Para a realização desta investigação foram adotadas como estratégias metodológicas, pesquisas qualitativas, descritivas, bibliográficas, observação, registros fotográficos, protocolos (relatos de estágio) dos experimentos. A partir da análise de resultados dos experimentos obtidos, fornecer propostas pedagógicas relativas ao ensino do teatro e ao seu aprendizado, frente à necessidade de uma maior contribuição no ensino do teatro nas escolas e comunidade macapaense, no que tange despertar do senso crítico e reflexivo.

Palavras-chave: Teatro dialético, Aprendizagem, Pensamento crítico/reflexivo.

\begin{abstract}
:
The main goal of this research is to work the dialectic in the classroom and communities at Macapá-Ap, starting with Brecht's action models and other didactic texts also in the Brechtian perspective. For the accomplishment of this investigation was adopted as methodological strategies qualitative research, descriptive, bibliographical, observation, photographic records, protocols (internship reports) of the experiments. From the analysis of the results about the experiments obtained, were provided pedagogical proposals regarding teaching theater and its learning, due to the need for a greater contribution of the teaching of theater at schools and the communities of Macapá, in what concerns the awakening of the critical and reflexive sense.
\end{abstract}

Keywords: Dialectical theater, Learning, Critical / Reflective Thinking 


\section{Introdução}

Este artigo apresenta a ideia que deu início ao trabalho de conclusão de curso surgido durante a disciplina de Prática Pedagógica ministrada pelo professor Me. Flávio Gonçalves na turma de VI semestre de Licenciatura em teatro, pela Universidade Federal do Amapá - UNIFAP. Em um primeiro momento, ainda no VI semestre, foi trabalhada pelo professor de Prática Pedagógica, a peça didática Aquele que diz sim, aquele que diz não de Bertolt Brecht, num processo de montagem e discussões e foi finalizado com três apresentações junto com mediação entre os acadêmicos e o público, como proposta da matéria de prática pedagógica.

Num segundo momento, durante a realização do Estágio supervisionado IV (VII semestre do curso de licenciatura em teatro), percebeu-se que a partir das referências dos textos didático de Brecht, bem como seu processo prático, poderia ser explorado o teatro dialético, visto que não se trata somente de teatro com finalidade espetacular e sim de um processo que perpassa pela aprendizagem, pedagogia. Além de contribuir com o despertar do senso crítico, presente na matéria de filosofia; levando os envolvidos à saírem da sua zona de conforto para refletir, questionar e principalmente, reformular novas ideias, com base no plano de ação inicial, abordando temas contemporâneos. Tais práticas de estágio, no período de observação, evidenciaram que era presente o método de educação bancária, ainda persistente nas escolas de Macapá, nos tempos hodiernos. A alienação denominada por Paulo Freire sempre nos instigou a possibilidade do fazer teatral voltada para a pedagogia, de modo a contribuir para essa desalienação. Nesta mesma visão no estudo de Ingrid Koudela (1999), afirma que a prática teatral é definida por Brecht como uma proposta de educação freiriana. Segundo ela, "a peça didática propõe o exercício de uma 'didática não depositária' (Freire, 1970), pela qual o aluno constrói o conhecimento e avalia até onde caminhou com o conteúdo, em lugar de se ver confrontado com um objetivo de aprendizagem pré-determinado" (KOUDELA, 1999, p. 114).

Motivados por esta inquietação, aliados a teoria e prática de Brecht, com base em seu poder educacional, buscou-se concretizar a ideia através de experimentos que se realizaram durante os processos de estágios supervisionados IV e V. O primeiro denominado "simbiose textual-costurando uma ideia rumo à dialética", pelo fato de termos incluído pequenos trechos do modelo de ação Aquele que diz sim/aquele que diz não, de Bertolt Brecht, ao texto didático dos 


\section{enquanto estratégia de fortalecimento do pensamento crítico/reflexivo na sala de aula e nos espaços comunitários de Macapá}

autores Laildson Leonardo de Lima e Adriano Alves (ambos paraibanos e professores de contabilidade), resultando ênfase ao texto. O segundo com subtítulo "Revivendo nos espaços da comunidade", com resultados voltados para relatos dos participantes e utilização de espaços alternativos, tendo como base o modelo de ação $A$ exceção e a regra, também de Bertolt Brecht.

\section{Simbiose textual-costurando uma ideia rumo à dialética}

O experimento I iniciou em maio de 2017, na Escola Estadual Nancy Nina Costa, em 3 turmas do segundo turno do ensino médio, cada turma composta por 40 alunos. Convidamos os educandos a fazerem uma leitura dramática. A escolha do texto se deu devido à necessidade de nos adequarmos ao plano de curso da escola que abordava o tema: meio ambiente, no conteúdo de artes. O texto $O$ planeta terra diz: Socorro fala da história de um julgamento, o qual o réu é o próprio ser humano. Um relato sério e importante sobre a poluição do ar, da água, do meio ambiente em si. A partir do texto de Laildson e Adriano, foram acrescidos fragmentos do modelo de ação de Brecht Aquele que diz sim/aquele que diz não; a narração adaptada por nós, para terceira pessoa no pretérito perfeito, teve propósito de evidenciar o distanciamento e caracterizar mais o texto em questão, como um exemplo mais próximo aos textos didáticos de Bertolt. Exemplo:

\section{Trecho original (início)}

\section{CENA I}

Promotor: segunda-feira, __/_/ 2017, Processo número 1/2017, Acusação: Destruição do Planeta Terra, Acusante: Mãe Terra, Acusado: Ser humano. Todos de pé para recebermos o excelentíssimo senhor JUIZ da primeira vara de direito penal e defesa da natureza.

Juiz: Pode sentar, declaro essa secção aberta.

Promotor: Iniciemos nosso júri, com as acusações e as devidas testemunhas, contra o réu: O Ser Humano.

Trecho modificado (acréscimo do coro)

\section{CENA I}




\section{O GRANDE CORO - O mais importante de tudo é aprender a estar de acordo. Muitos dizem sim,} mas sem estar de acordo. Muitos não são consultados, e muitos Estão de acordo com o erro. Por isso: O mais importante de tudo é aprender a estar de acordo.

Promotor: segunda-feira, __/_/ 2017, Processo numero 1/2017, Acusação: Destruição do Planeta Terra, Acusante: Mãe Terra, Acusado: Ser humano. Todos de pé para recebermos o excelentíssimo senhor JUIZ da primeira vara de direito penal e defesa da natureza.

Juiz: Pode sentar, essa secção é declarada aberta.

Promotor: Iniciemos nosso júri, com as acusações e as devidas testemunhas, contra o réu: O Ser Humano.

Segundo Fernando Peixoto, Brecht nutria uma grande paixão por tribunais, sendo o tribunal um ambiente propício para trabalhar a dialética, "grandes processos judiciários, para que os tribunais fossem obrigados a tomarem decisões diante do conjunto da população" (1979, p. 110).

Levando em conta este aspecto, considerou-se que o texto O planeta terra diz: Socorro, teria condições de ser trabalhado a fim de proporcionar o exercício da dialética que Bertolt preconiza, além de abordar a relação do homem com o meio ambiente, levando os educandos a vivenciarem os dois lados de uma audiência (autor e réu).

O coro para Brecht propõe provocar o chamado "efeito de distanciamento". Diferentemente dos coros gregos que intensificavam a ação, em Brecht, eles provocam uma quebra na ação, de maneira a despertar o espectador e então alcançar o efeito didático. Além disso, o fato de o dramaturgo alemão resgatar um elemento da tragédia e inseri-lo no teatro moderno provoca uma estranheza para o público, o que também contribui para o "efeito de distanciamento". Souza define o coro como:

(...) um sujeito observador de cena, o qual vê o objeto (cena) em construção. Dessa maneira, o coro apresenta-se como mediador entre cena e público; logo, a informação recebida pelo espectador é construída tanto pela cena quanto por comentários desse observador privilegiado, fazendo com que o público vislumbre um ponto de vista, uma opinião acerca da ação, sem que seja a única e a que devam adotar. (1997, p. 13)

De acordo com esta afirmativa, seguindo a lógica de Souza, o uso do "coro" seria um dos meios para causar o distanciamento, proposto na estética de Brecht. Essa foi nossa intenção no 


\section{enquanto estratégia de fortalecimento do pensamento crítico/reflexivo na sala de aula e nos espaços comunitários de Macapá}

primeiro trecho do texto $O$ planeta terra diz socorro.

No aspecto prático deste primeiro experimento, utilizamos o "sistema coringa" de Augusto Boal aos demais personagens, como nos casos do juiz, do ser humano, da dona de casa e do empresário; a intenção foi proporcionar aos jovens a possibilidade de viver mais de uma situação, pois houve a disputa de papéis. Por se tratar de poucos personagens, no texto, e muitos participantes na atuação, incluímos o coro dentro do sistema coringa, ou seja, as trocas de personagens eram e duplas ou trios, dependendo da quantidade de alunos que sentiam-se interessados por determinado papel. Deste modo, ousamos nos apropriar desta particularidade, embasados na estrutura aberta que os textos didáticos brechtianos possuem; nos dando liberdade para incluirmos trechos, fragmentos do modelo de ação Aquele que diz sim/aquele que diz não. Pois, segundo Doumien Koudela, "Os textos das peças didáticas de Brecht permitem uma multiplicidade de interpretações, sendo possível criar, a partir deles, novos modelos de ação". (1992 p.14-15).

O ambiente escolar nos proporcionou pouca abertura para que pudéssemos iniciar nosso projeto em conciliação com o currículo escolar. A partir dos resultados deste experimento, criaram-se outras possibilidades de pensamento e a sua relação com o ambiente externo, para a realidade cotidiana do mesmo. Ao final do texto $O$ planeta terra diz: socorro, um questionário com perguntas, cujo propósito foi protocolar reflexões para o nosso acervo e colocar em prática uma situação com duas possibilidades de reflexão/desfecho, servindo também como avaliação final para a instituição na qual atuamos. Trecho a seguir:

\section{Júri popular}

1. Você concorda com os argumentos da Mãe Natureza? E do Ser Humano?

2. Os carros poderiam existir sem a poluição?

3. Os argumentos do Ser humano estão corretos?

4. O ser humano viverá com a poluição por muito tempo?

5. Esta poluição é realmente necessária?

6. O que podemos fazer para reverter esta situação? Como podemos fazer isso? 


\title{
O SER HUMANO É CULPADO E DEVE SER CONDENADO, OU MERECE UMA SEGUNDA CHANCE? POR QUE?
}

\author{
( ) Culpado ( ) Inocente
}

Neste experimento apesar da dificuldade de adequação inicial da nossa proposta com plano de curso da escola. Apesar de o próprio livro da escola Arte em Interação (capítulo 7, p. 257) recomendar que fosse trabalhado o texto Aquele que diz $\mathrm{sim} /$ aquele que diz não em seu currículo, além de sugerir possíveis aplicações da ideia. Houve relutância no uso do modelo de ação, sugerido por nós, mesmo que respaldados no livro didático oferecido pela instituição, pelo simples fato de o tema "meio ambiente", ser uma exigência naquele momento. Restou-nos incluir características do modelo de ação de Brecht, ao texto didático O planeta terra diz socorro de Laildson, já elucidado anteriormente. Mostrando-nos a importância do diálogo com a instituição para a execução de um projeto em que ambos se beneficiaram.

Com termino deste experimento, analisamos que poderia ser enriquecedor para a instituição, implantar um laboratório de teatro, com esta linha de pensamento, pois desta forma diminuiria a distância entre corpo docente e corpo discente, visto que o resultado das reflexões funcionariam também como diagnóstico para se trabalhar possíveis apontamentos, mesmo que subjetivos, tanto nas relações de interação, poder, tomada de decisão, paradigmas e outros levantamentos, por parte do corpo docente, como também as questões que propusemos, voltadas para a prática pedagógica, aprendizagem.

Neste contexto, Lev Vygotsky afirma que é preciso perceber as contradições do mundo externo para se compreender a arte. Em relação à percepção, o autor diz que o mundo é compreendido não apenas como cores e formas, mas com sentido e significação:

[...] toda percepção humana consiste em percepções categorizadas ao invés de isoladas. [...] A transição, no desenvolvimento para formas qualitativamente novas, não se restringe a mudanças apenas na percepção. A percepção é parte de um sistema dinâmico de comportamento; por isso, a relação entre as transformações dos processos perceptivos e as transformações em outras atividades intelectuais é de fundamental importância. (VYGOTSKY, 1989, p. 37-38). 


\section{TEATRO DIALÉTICO: \\ enquanto estratégia de fortalecimento do pensamento crítico/reflexivo na sala de aula e nos espaços comunitários de Macapá}

O fazer teatral age, na Zona de Desenvolvimento Proximal de Vygotsky, em situação de interação e cooperação entre a criança e seus colegas com a supervisão do professor e cria, por outro lado, novas ZDPs. Ricardo Japiassu (1998), segundo sua pesquisa com atividades teatrais na escola pública, assegura:

As implicações escolares-educacionais e pedagógicas do paradigma histórico-cultural do desenvolvimento humano, nas quais se insere a proposta de ensino do Teatro apresentada com o presente trabalho, assinalam a importância do que se pode fazer com ajuda de outros mais capazes e experientes e o que se faz sozinho, entregue à resolução solitária de problemas, ou ao isolamento cultural em determinado. A qualidade das interações intersubjetivas, culturalmente mediadas, interfere decisivamente no processo de constituição dos sujeitos. (JAPIASSU, 1998, p. 9).

Fica assim fundamentada por Lev Vygotsky e Ricardo Japiassu, a ideia de que o teatro dialético pode interferir no processo da construção de sujeitos, por meio de interação. Para Jean Piaget, "é impossível negar que a pressão do meio exterior desempenha um papel essencial no desenvolvimento da inteligência" (PIAGET, 1966, p. 337). Sendo o meio importante para o desenvolvimento intelectual, logo as peças didáticas possibilitam a admissão do meio dos participantes através do "modelo de ação", em que "deve ser concretizado com material trazido pelos jogadores, oriundo de seu cotidiano" (KOUDELA, 1992, p. 14).

O teatro dialético como proposta pedagógica para a instituição, daria oportunidade para, além de despertar o senso crítico e reflexivo, tirar proveito deste resultado para melhorar as relações e situações complexas, dificilmente de serem diagnosticadas e/ou abordadas de forma objetiva, pelo corpo docente.

\section{Revivendo nos espaços da comunidade}

Concluída esta reflexão, resultado do experimento I, iniciamos o experimento II, terceiro momento desta pesquisa; realizada no conjunto habitacional São José, localizado no bairro buritizal. Público alvo, jovens da comunidade, com faixa etária de 15 à 20 anos de idade.

Nos oportunizamos do momento de estágio V, para colocar em prática este II experimento, com temática "comunidade" e nos propusemos a levar as estéticas de Brecht aos jovens do Conjunto habitacional, através do Projeto Acenda uma Luz pelo Centro de artes Talentos, 
idealizado por Cayton Farias, ator, diretor, e professor de dança. Nos sentimos mais à vontade para trabalhar de acordo com nossa logística; a ausência de imposições nos possibilitou uma abertura maior e oportunidade para fazermos levantamento das questões que percorriam a comunidade. A partir destas questões, escolhermos um plano de ação de Brecht, de modo a contextualizar a realidade dos envolvidos. Após os levantamentos, apresentamos ao grupo de jovens da comunidade, três modelos de ação: Baden Banden, Aquele que diz sim/aquele que diz não, A exceção e a regra de Brecht.

Os temas levantados pelos jovens foram: aumento da passagem de ônibus; relação patrão empregado nas empresas privadas; racismo; desrespeito ao homossexual, transexual; falta de oportunidade no mercado de trabalho para jovens que saem do ensino médio; perda do direito de ir e vir, devido à falta de segurança pública.

Após as argumentações e a demonstração dos textos que oferecemos como proposta de experimentação, o Modelo de ação "A exceção e a regra" caiu no gosto dos participantes. Após a escolha do texto, buscamos fazer a contextualização com os levantamentos de temas abordado por eles.

O modelo de ação $A$ exceção e a regra, apresenta um modelo da discussão de um tema através de uma ação sólida. O tema é a dominação de classe, a injustiça disfarçada de justiça. A ação é a relação entre patrão e empregado numa caminhada pelo deserto para alcançar uma busca ao petróleo. SINOPSE: O tema de $A$ exceção e a regra, como mencionado acima é a divisão de classes reinante na sociedade capitalista, de como nela as relações de poder se naturalizam e, ao mesmo tempo, se tornam desmedidas. Um comerciante viaja pelo deserto com um carregador, seu empregado, na tentativa de conseguir uma concessão de petróleo. Em consequência da condição climática surge a sede a falta d'água. Na calada da noite, o empregado se aproxima de seu patrão com algo nas mãos. Seu patrão acredita ser uma pedra e, para se defender, mata o empregado com um tiro. Acontece que o empregado se aproximava para the oferecer água. Mesmo o empregado (Cule) sendo inocente e tendo provas e testemunha (Guia) de sua inocência, é enfraquecido por sua condição social e outras questões que o texto aborda, como resignação, insegurança no emprego, resignação, falta de questionamentos. Mostrando uma injustiça que percorre até os tempos de hoje, em que o detentor de poder sempre sai no lucro e o socialmente inferior, mesmo tendo razões, por falta de conhecimento e informações, acaba sendo injustiçado. 
Percebe-se, neste modelo de ação, que apesar de ter sido escrito em 1929, possui familiaridade com nosso tempo vigente. A partir dessa familiaridade com a atualidade, escolheuse o modelo proposto $A$ exceção e a regra que faz relação com abuso nas relações do homem com homem, relação patrão-empregado, um dos temas levantados pelos jovens.

A partir dessas preliminares, o tema conciliado ao modelo de ação, demos início à construção coletiva com o grupo de jovens da comunidade. Ao terem o primeiro contato com o modelo de ação $A$ exceção e a regra, durante a leitura dramática, sugeriram diversos espaços na própria comunidade, para composição do cenário, que se passou num local aberto, com areia, dando a ideia de deserto. Da mesma forma passamos a compor outros cenários.

Após vivencia de cada cena, uma roda de conversa em que os participantes tinham a liberdade de contextualizar a situação apresentada, sob nossa mediação. Um jovem militante, levantando questões trabalhistas, fez a seguinte analogia:

O guia seria o funcionário questionador, esperto, uma espécie de gerente que recebe ordens, embora não concorde em parte. O cule, o funcionário desprovido de informações sobre seus direitos, trabalhador não sindicalizado e que teme perder seu emprego; o comerciante, patrão explorador que se ampara no poder do capital e em ações antiéticas, respaldando-se em documentações forjadas, como folha de ponto pré-datadas, roubando direitos dos empregados e sendo causador de assédio moral (participante "G. B". 18 ANOS).

Percebemos neste pensamento, uma reflexão compartilhada com outros jovens do grupo. Uma reflexão e crítica ao sistema trabalhista que tem suas raízes na história antiga.

$\mathrm{Na}$ ocasião em que estava sendo experimentada a cena final (o julgamento), os jovens sugeriram que fosse utilizado outro espaço, semiaberto, com estrutura de um tribunal, local onde acontecia os cultos religiosos. Por ocasião, o espaço estava organizado com cadeiras, palco, microfone, pois ali aconteceria um culto. Solicitamos o local por uma hora de tempo, para colocarmos em prática a cena, como foi acordado com o responsável pelo local. No espaço, algumas pessoas que aguardavam o culto deram veracidade ao nosso experimento, a parte mais realista de tudo. Nosso pequeno público que assistia a tudo, com estranheza no olhar.

Ao finalizar esta cena, dirigimo-nos ao outro espaço para uma roda de conversa, mediada por nós, somente com os participantes da encenação, pois o culto local iria começar. Durante a roda um atuante relatou situação familiar que vivenciou próximo de seu lar, em que o pai de um 
colega, foi insensivelmente demitido por "justa causa", pelo fato de frequentes faltas, por questões de saúde, acarretando demissão, dívidas, desgosto e posteriormente falecimento do mesmo, sem mínimas condições de manter a família. A viúva estaria sendo representada por este recorte do modelo de ação $A$ exceção e a regra, a história de vida de uma senhora, um jovem, que tentaram reverter a situação entrando com uma ação contra a empresa, porém, na falta de conhecimento da Lei e provas, houve perda de causa. Embora a lei trabalhista exista para amparar o trabalhador, é o capitalista que se apropria dela, de forma desleal, utilizando-se da própria Lei para derrubá-la, através das conhecidas "brechas", aliadas às atitudes antiéticas.

Esta vivência permitiu aos jovens jogadores, do conjunto São José, partilharem de suas experiências de vida, a sua vivência de mundo, questionando situações já vividas e vistas como comuns. A partir do texto, foi possível relembrar de outra forma, a partir de questionamentos de como é e como poderia ou pode ser os fatos que ocorrem em nosso dia a dia.

\section{Considerações finais}

Esta pesquisa está em andamento, e pretende ser finalizada no primeiro semestre de 2018, como quesito final do curso de licenciatura em teatro. O principal objetivo em questão é, promover a dialética com jovens e adultos, dentro e fora da escola, a partir de modelos de ação de Brecht e outros textos didáticos, para o ensino do teatro nas escolas e comunidades da cidade de Macapá.

A partir da análise dos resultados desta pesquisa, pretende-se vivenciar e compartilhar informações, reflexões através do teatro dialético de Brecht. Nos experimentos I e II, não houve uma preocupação de caracterizarização de personagens, mas de transmissão de conceitos construídos socialmente e transformação destes conceitos em outras possibilidades de ver o mundo. Utilizamo-nos das experiências pessoais dos grupo, para através deste projeto, fornecer material, discussões e aplicações práticas, destinado a profissionais docentes, discentes e demais interessados.

\section{Referências}

DESGRANGES, Flávio. A pedagogia do espectador. São Paulo: Hucitec, 2010. 
FREIRE, Paulo. Pedagogia da autonomia. Editora Paz e Terra S/A. São Paulo-SP, 2002.

JAPIASSU, Ricardo. Metodologia do ensino de teatro. São Paulo: Papirus, 2001.

KOUDELA, Ingrid Dormien. BRECHT: um jogo de aprendizagem. Editora perspectiva. 2010.

KOUDELA, Ingrid Dormien. Jogos Teatrais. São Paulo: Editora Perspectiva, 2001.

LUNA, Sergio Vasconcelos. Planejamento de pesquisa. Editora PUC SP- $2^{\circ}$ edição.

CONCíLIO, Vicente, Baden Baden - Modelo de ação e encenação no processo com a peça didática de Bertolt Brecht. Paco Editorial SP, 2016.

BOZZARRO, B. Hugo; Perla Frenda; Tatiane Cristina Gusmão. Arte em interação- Manual do professor (Ensino Médio) PNLD 2015,2016,2017. Ministério da Educação.

Artigo submetido em 04/11/2018, e aceito em 10/02/2019. 